Joshua Wells, Christopher Parr and Stephen Yerka

\title{
9 Archaeological Experiences with Free and Open Source Geographic Information Systems and Geospatial Freeware: Implementation and Usage Examples in the Compliance, Education, and Research Sectors
}

\subsection{Introduction}

Geographic information systems (GIS) have today become a recognizably standard series of tools within the archaeologist's kit. The continued proliferation of relativelycheaper computing power worldwide has meant that the number of hardware, operating system, and software limitations to GIS utilization have been on a steady downward trajectory for the last quarter century. As these personal computer barriers to GIS usage crumbled, the general trend toward improved Internet connectivity (wired and wireless, and certainly not globally achieved) has permitted archaeological geospatial investigators to better share their finished products and base data within the professional community and with interested publics; also to allow archaeologists to avail themselves of growing stores of public and private geospatial data related to the earth and environmental sciences. The remaining and significant barriers to GIS usage in archaeology, however, are the costs and availability of GIS software packages themselves since the most popular GIS applications are proprietary, expensive, and bogged-down with license-based user restrictions that serve to limit the practical implementation of the software for legal reasons. These last two barriers are particularly pernicious for archaeologists, whose laboratories frequently do not have the highest funding priorities in even the best of economic times, and thus creates functional limits to the scope of GIS deployment among the archaeological community. These fee-and-license restrictions in the workplace have served to effectively hobble more thorough development of archaeological GIS and database training among universities and professional development outlets, which has helped to maintain the current climate in which archaeological GIS training and sensibilities remain somewhat esoteric even in a time of rampant technological changes throughout the sciences and humanities.

Fortunately, a potential solution to the fee-and-license barriers exists. This paper

Joshua Wells: Indiana University South Bend, South Bend, USA

Christopher Parr: Virginia Department of Military Affairs,Virginia, USA

Stephen Yerka: University of Tennessee, Tennessee, USA 
demonstrates and evaluates the use of free and open-source (FOSS) GIS software in the pursuit of several projects related to heritage management and archaeological reconnaissance. The strengths and weaknesses of Quantum GIS (QGIS) as it pertains to several archaeological projects will be discussed in detail, along with briefer assessments of other FOSS and free-ish applications such as the User-Friendly Desktop GIS (uDIG), and Google Earth (which is definitively not FOSS, but freeware).

The projects to be discussed include the interoperation of landscape-scale spatial databases from heritage management offices in several US states, the management of archaeological projects on an American military base, and the use of software applications to promote GIS and general geospatial training in undergraduate education and research. This is not an exploration of GIS methods in archaeology, we assume most readers today are basically familiar with what GIS packages do (database mapping, spatial statistical analyses, layering of data, etc.); nor is this a "how-to" guide for GIS methods with FOSS softwares, although we do include references to a number of good training materials. Instead, particular emphasis will be given to the ways in which the different FOSS GIS software discussed can be integrated with a professional workflow in archaeological research, educational, and outreach settings. Through these examples, interested archaeologists with GIS experience will better understand the differences between their fee-and-license products and FOSS products, and archaeologists interested in GIS experience will have a reference base from which to enter the world of FOSS GIS training materials.

\subsection{What Geographic Information Systems and Free and Open Source Software are not}

Although we assume some basic familiarity with the products of GIS and the existence of some software packages, it seems prudent to briefly clarify what a GIS system generally is not and is so that the FOSS distinctions are more readily apparent in the examples below. A GIS is a software package that combines database behaviors with spatial representations in order to create, manage, and analyse spatial data. Conversely, and simply put, a GIS is not an ESRI product. Although ArcGIS (ArcInfo, ArcView, ArcMap, etc.) is a GIS, there is much more diversity in geographic information systems as a population of software than is generally recognized. To many people, even learned professionals, the term GIS is often (unfortunately) a shorthand for ESRI products (or some other license-restricted software such as Erdas Imagine, Manifold, etc.). This terminological imprecision about GIS is simply a feature of marketplace dominance, in the same way that many residents of the United States refer to cellophane tape as "Scotch" or disposable tissues as "Kleenex" the use of "GIS" is often considered ArcGIS use. Fortunately, there are a number of resources available with extensive listing of many license-restricted and open-source GIS softwares, past and present (Dempsey, 
2012; OSGeo (Open Source Geospatial Foundation), 2013b; Sherman, 2012; Steiniger, 2013; Steiniger and Bocher, 2009; Steiniger and Hay, 2009; Steiniger and Hunter, 2013; Wikipedia, 2013).

The influence of ESRI over discussion of GIS is so pervasive that even the basic language of data types is beholden to ESRI: the shapefile, actually a set of three or more files that function together for the display and management of vector data (points, lines, and polygons), was developed by ESRI in the early 1990s for use with its ArcView product, but is used in practice as an open standard that is regulated by ESRI (ESRI, 1998); the similarly open ESRI Geodatabase standard (ESRI, 2013), with several different formats for spatial databases, is often referenced colloquially as simpler name for a spatial database.

Some important caveats, regarding the professional environment for GIS in which archaeologists participate, are worth stating: (1) although ESRI is often criticized (lovingly or otherwise) for its market dominance, it is worth mentioning that each author on this paper is also a highly-trained user and customer of ESRI and other proprietary products; and (2) market dominance is an important feature of the social landscape to which all archaeological practitioners must adapt. There are important functional differences in work processes that use FOSS GIS to complete finished products for dissemination, and those that use FOSS GIS to share processed data with distant offices that use other proprietary software. Each reader must analyse their own needs, resources, and choices in both the technical and social landscapes in order to determine the best course of action for the professional or institutional adoption of any new software (e.g., Sherman 2012, cf. Kling et al. 2005).

As discussed elsewhere in this volume, free and open-source software is also a frequently misunderstood concept among the general public, including the scientific and humanities communities (outside of the computer sciences, where they are then otherwise debated). The word "open" generally refers to the availability of intelligible source code and the rights of users to review and modify it. The "open" designation is frequently mistaken to mean "zero cost". A popular adage in the open source community clarifies different senses of the term "free", where "free as in speech" refers to human rights and liberties for expression, while "free as in beer" simply refers to goods or services available without a monetary charge. The free-software movement, fully cognizant of the labor-costs invested in creating software, emphasizes the "free as in speech" civil liberty aspects of open source code. In her ethnographic account of the open source movement, anthropologist Gabriella Coleman (2013, p. 200-205) demonstrates how open source programmers engage in a particularly effective form of cultural critique, particularly a critique of the commoditization of intellectual labor and expression through normative, highly-restrictive (crippling "free as in speech") intellectual property practices. Differing definitions for the exact meanings of the terms free and open, hearkening to debates that began in the earliest days of free and opensource movements, continue to slowly proliferate today (e.g. Creative Commons 2013; Open Source Initiative 2013; Raymond 2000; Sherman 2012; Williams 2002). Through- 
out this discussion, we will clarify exactly the modes of "free" and "open" made available by the development communities for each software presented; this is done for the sake of clarity, and in recognition of the fact that because of often limited research budgets and personal penchant, archaeologists may be also interested in free beer.

\subsection{What does Open Source mean in GIS}

\subsubsection{Pros and Cons}

The particular software applications discussed here are by no means a complete representation of all available FOSS GIS offerings, but are the applications represented in the use case example sections below. Descriptions are provided for completeness, and we encourage potential users to investigate the documentation for any software named here. Any potential user of FOSS software (GIS or otherwise) should explore their work cycle and consider the strengths and weaknesses of each application in context. A tremendous benefit of FOSS software is that you can experiment with it to learn these details. It may also be useful to have a frank discussion with institutional IT personnel (if available) to ask what advice and support they can provide for laboratory and broader usage within the institutional framework (we have found our IT staffs to be both very interested in new FOSS software and helpful in solving conflicts before they arise).

\subsubsection{Software Application Summaries}

Quantum GIS (QGIS). This is a full-featured, graphical user interface, desktop GIS application. QGIS installs on Linux, Mac, or Windows operating systems (there is also a mobile Android application) with dozens of language translations for installation. In terms of use and feature prowess, the best analogy is that QGIS is to the ArcGIS-like proprietary GIS software world what OpenOffice and LibreOffice are to the proprietary MS-Office-like office software world. Begun in 2002, the Quantum GIS project since 2007 has been a project of the Open Source Geospatial Foundation (OSGeo), throughout its lifespan it has a fairly frequent update cycle averaging about four months between releases.

QGIS users can employ ESRI shapefiles, personal geodatabases, and coverages, also KML, and numerous other filetypes for vector data. Numerous raster data types are also supported, including ESRI grids, GeoTIFF, and Erdas Imagine; complex raster manipulation is accomplished with QGIS tools that interface with GRASS (another FOSS GIS software that installs automatically with QGIS). Supported databases include aforementioned ESRI personal geodatabases, PostGIS, and Spatialite, among 
others. The most recent version of QGIS (2.0) supports a nuanced map composer for high-quality cartographic output (Ross et al., 2013).

Two high-quality QGIS instruction books have recently been published by Graser (2013) and by Thiede et al. (2013). There is a robust user community for support, facilitating the development of numerous official and third-party plugins, help forums, blogs, and multimedia instructional materials. As a FOSS application, QGIS is made available through the terms of the GNU General Public License which guarantees the rights of users to use, copy, and modify the software (the source code is available). Official QGIS documentation is all covered by a Creative Commons Attribution-ShareAlike license that allows users to share, adapt, and use those materials for commercial purposes with the conditions that the original source is attributed and derivative products will be shareable as well (Creative Commons, 2009).

The User-Friendly Desktop GIS ( $u D I G)$. This is a full-featured, graphical user interface, desktop GIS application that runs on Linux, Mac, or Windows operating systems through the use of a Java virtual machine (this is a common design strategy for cross-platform software, Java is easily downloaded for free or may already exist on your computer). In terms of use and features, uDIG is a viewer as much as an editor. It gives users the useful ability to drag and drop supported filetypes into the application, including URLs for geospatial web services. Although uDIG supports many vector geospatial formats, inluding ESRI shapefiles and KML; the raster functionality is mainly focused on image overlays, which in the case of aerial imagery or scanned maps may be of important interest to archaeologists. Map creation through a specialized editor is straightforward and uncomplicated. The user community for $\mathrm{uDIG}$ seems smaller, but fairly active; the developers of uDIG provide a great deal of documentation and also a YouTube channel with numerous how-to videos. uDIG is based on the Eclipse Rich Client Platform and is made available through the terms of the Eclipse Distribution License which allows redistribution and modification of the software (the source code is available) but without the endorsement or liability of its creator (Eclipse Foundation, 2007).

Google Earth. This is neither a true GIS, nor open source (although it is zero cost at the entry level), but is a powerful virtual globe application, with data creation and editing capabilities, that installs on Linux, Mac, or Windows operating systems (with less functional versions available for iOS and Android). In terms of use and features, Google Earth is a viewer as much as an editor that utilizes drag-and-drop functionality to overlay vector and raster data on top of Google's proprietary delivery of detailed aerial imagery and topographic relief. The basic datatype for storing Google Earth information is KML (an XML variant that can also contain linked data like hyperlinks and image links); numerous FOSS and proprietary tools exist to convert various geospatial data types to KML (QGIS and UDIG do this), also fee-based Google Earth Pro has conversion functions. There is a highly robust user community for Google Earth that produces and shares KML data sets; the public accessibility and visibility of this resource is a definite strength for archaeologists interested in sharing their data profes- 
sionally or publicly among users who may not have definitive GIS skills or access (e.g. Hochstetter et al. 2011; Beale 2012; Harris 2012). As a proprietary product and service that is made available freely (as in free beer) there are significant restrictions on the reuse of Google's content, however Google generally allows for fair use research products like print media (Google 2012, 2013).

Other FOSS GIS applications Archaeologists may find uses for other software such as GRASS (aforementioned), gvSIG (similar to uDIG), Marble (similar to Google Earth), OpenJump (similar to uDIG), NASA World Wind (similar to Google Earth but geared for software developers). There are good compilations of numerous FOSS GIS applications for the GIS planning and natural science communities (Steiniger, 2013; Steiniger and Hunter, 2013) that may be useful for comparative purposes.

People who wish to experiment with a wide variety of FOSS GIS applications with little difficulty or investment may wish to try the OSGeo Live Disk (OSGeo (Open Source Geospatial Foundation), 2013b,a), a Xubuntu Linux system that is designed to be loaded on a flash drive or burned to a DVD. A test user may boot their computer with the disk and use the software without changing the operating system or the persistent memory of the computer. The annual release of the OSGGeo Live Disk is celebrated by users at the international Free and Open Source for Geospatial (FOSS4G) conference as an important tool to help develop geospatial competencies in all manner of user communities.

\subsection{Use Case One: FOSS GIS with Heritage Management Data}

For professionals who use legacy archaeological heritage management data, and create new data sets - whether for compliance, research, outreach, or all - a FOSS GIS application is an excellent tool for conducting work. In the example presented here, Quantum GIS was used to edit and visualize archaeological site data from several State Historic Preservation Offices (SHPOs) in the Midwestern United States. An important duty of a SHPO is to maintain a database that describes the preservation status and potential information value of all known historic and prehistoric cultural resources within a state's jurisdiction (Neumann and Sanford, 2001). These databases are mainly used for heritage management and coordination with other government services, but aspects of them can have excellent potential for research and modeling. Governmental practice in the American federal system has resulted in the creation of many unique state site database file structures that are not necessarily interoperable. Although they all contain comparable archaeological descriptive data with scientific value, these are recorded in various formats to suit local software requirements and the shorthand of local government paperwork. Importantly, however, the functions of geospatial data management do provide some cross-cutting file types which can be used to begin to evaluate the intersections of the data within them. The relationships of similar archaeological sites within two different SHPO databases is somewhat anal- 
ogous to that of electronic patient records in the medical sector. Two different clinics may treat patients with similar conditions but keep distinctly differently organized databases. Each clinic necessarily uses official jargon for qualitative descriptions and recognized standards for metrics, but an expert is required to interoperate both sets of records into a contiguous and analytical set (Andersson et al., 2003; Kaplan et al., 2003; Thiru et al., 2003). QGIS as a full-featured GIS is an good choice for the assessment, query, and translation of these data sets. The archaeologist can immediately grasp the spatial aspects of the complete sets and derived queries, and begin to consider ontological plans for interoperation.

The goals of this exercise (full details available in Wells 2011) were to create one interoperable data set from four SHPO archaeological databases in order to shed light upon the potential of these cybertools (Kintigh, 2006; Snow et al., 2006) to be used in analytical functions regarding landscape distributions, site functions, or other anthropological questions. The exercise used available GIS structures which were provided in original ESRI shapefile, personal geodatabase, and delimited text formats from their governmental sources. The site records under investigation describe components from the archaeological cultural tradition defined as Mississippian. These include farmsteads, villages, towns, and special use sites relating to numerous prehistoric agricultural polities with various hierarchical organizations throughout the American Midwest and Southeast, in the date range AD 1000-1500. Figure 9.1 illustrates the geographic scope of data sets involved within QGIS and its 3D globe plugin.

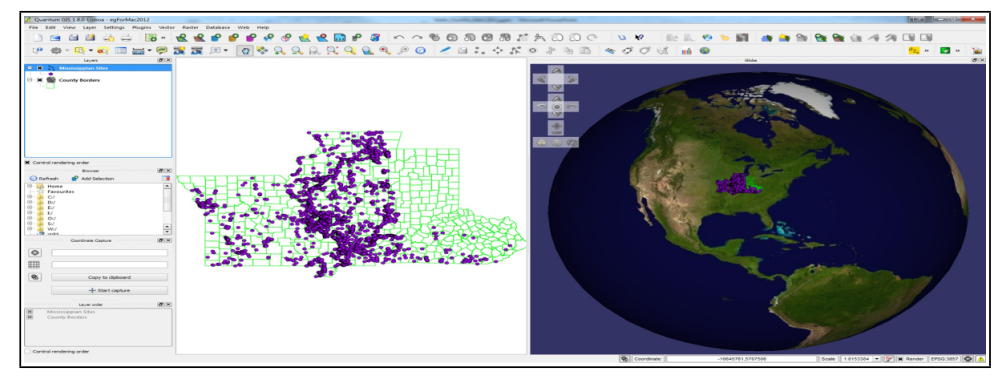

Figure 9.1: Mississippian sites from separate governmental databases in the Midwestern United States visualized through QGIS

This exercise demonstrates just one use of a FOSS GIS application to deal with public archaeological data available from government offices to qualified professionals. There is also a growing trend in publication of more open archaeological data resources related to heritage management on the Web that provide geospatial data for archaeological resources in ways that are both scientifically important and compliant with legal statutes and ethical imperatives for resource protections. Organizations such as the Archaeology Data Service, Open Context, the Paleoindian Database of the 
Americas (PIDBA), and the recently founded Digital Index of North American Archaeology (DINAA) project all make such geospatial data available for public use, and are excellent resources for exploring the potential for FOSS GIS.

\subsection{Use Case Two: FOSS GIS and Archival Management at the VAARNG Curation Facility}

The Virginia Army National Guard (VAARNG) Curation Facility at Fort Pickett (Blackstone, Virginia), which operates as a proponent of the Department of Military Affairs Facilities Management Office's Cultural Resources Management (CRM) Program, has served as the repository for the VAARNG Archaeology Collection since 2003. The collection consists of over 20,000 artifacts and records associated with more than 150 investigations at 14 training facilities and readiness centers throughout the Commonwealth in accordance with the National Historic Preservation Act (NHPA) and the National Environmental Policy Act (NEPA). Most of these, however, were conducted at Fort Pickett, which is a 41,000 acre Maneuver Training Center in the Southside Virginia Piedmont. In this respect, the curation facility has proven an invaluable resource for understanding the history of a region largely overlooked in Virginia's history.

From 2003 to 2012, the VAARNG Curation Facility had been ably administered by the Conservation Management Institute (CMI) of Virginia Polytechnic Institute and State University through a contract with the CRM Program. Now that the Department of Military Affairs has assigned a permanent Collections Manager to the facility, the CRM Program will continue to meet its statutory obligations regarding the curation of state and federal archaeological collections. However, the CRM Program will also leverage data management technologies and GIS to improve both the administration of the VAARNG Archaeology Collection and the overall effectiveness of the CRM Program in its support of the National Guard's mission.

One such innovation is the development of a purpose-built, MS Access-based collections management system, Lil'Sorrel (named for the locally famous horse of a Virginia Confederate general). This relationsal database system incorporates the Sonoma Historic Artifact Research Database (SHARD), a freely available database scheme promoted by the Society for Historical Archaeology (SHA) and the Anthropological Studies Center at Sonoma State University; although the structure of SHARD is considered public with attribution credit the database itself is distributed in a native MS-Access format (SHA (Society for Historical Archaeology), 2011). Lil'Sorrel has enabled the Collections Manager to account for every item in the VAARNG Archaeology Collection in real time at the artifact-, box-, and project- (or accession-) level. Lil'Sorrel was preceded by an earlier system, Lil'Benny 2.0, for a previous project detailed by Parr (2011); the earlier Lil'Benny system served as a working prototype for the relational model governing Lil'Sorrel, although certain modifications were required to meet the spe- 
cific needs of the VAARNG Curation Facility and the CRM Program. In an attempt to standardize the general functional classification system employed by Lil'Sorrel, the SHARD coding system was adopted but modified to accommodate prehistoric sites. The classification system and its associated lexicon are enforced by linking the necessary fields with (sometimes cascading) drop-down menus. These link to various "Options" tables, which can be accessed separately to allow new selections to be added as needed.

A database model for Lil'Sorrel is shown in Figures 9.2a and 9.2b. These inform the more than 80 queries, forms, and reports that have been developed to operate the system. Its most basic function is to account for the artifacts as they enter (e.g., accession), move through (e.g., exhibit, inspection, study), and leave (e.g., deaccession, loan) the VAARNG Curation Facility. Additionally, Lil'Sorrel has automated several routine tasks performed by the Collections Manager: it estimates the remaining "free space" available in the storage rooms; it generates loan agreements and provides notification of approaching due dates; it records and reports the daily environmental (e.g., temperature, relative humidity) readings inside the facility; and it documents any adverse incidents involving the building or the collection. Most importantly, Lil'Sorrel allows the CRM Program to track its artifacts "from screen to shelf” by georeferencing each to its original findspot. When combined with flexible search options, Lil'Sorrel enables the CRM Program (and by extension the contract archaeology firms it regularly employs) to plot, identify, and model artifact distribution patterns as never before.

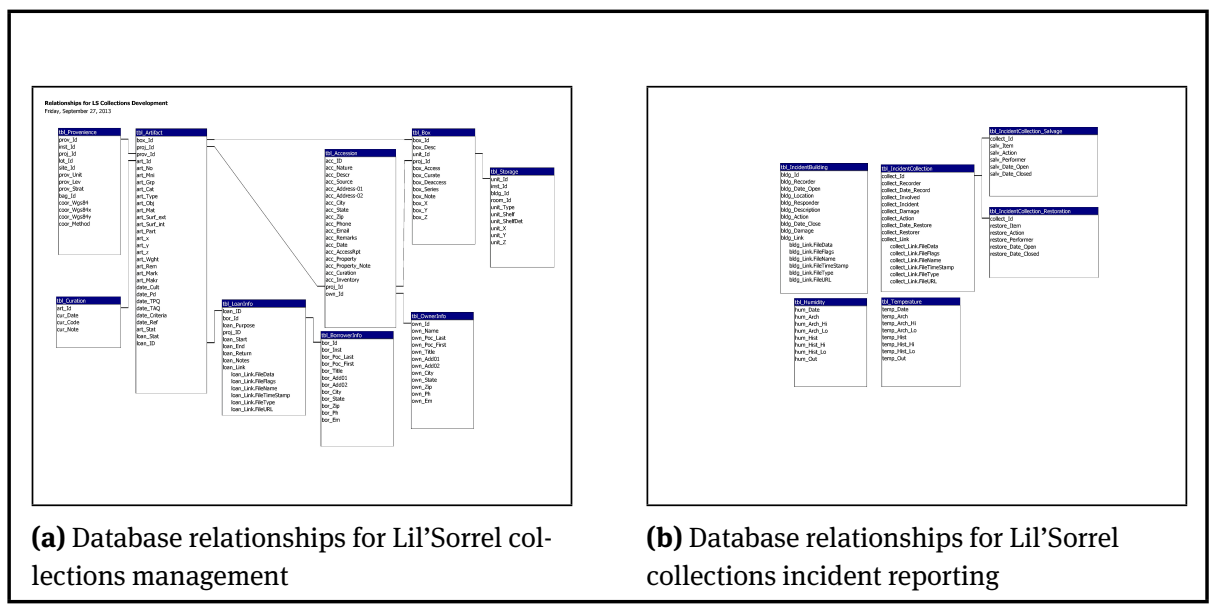

Figure 9.2: Database design

The example shown in Figure 9.3 illustrates some of the FOSS capacity for mapping archaeological collections through QGIS. Geological occurances of diabase dikes - shallow, intrusive igneous deposits of fine-grained and sometimes glassy rock - have been 
noted throughout Fort Pickett, and the CRM Program is investigating how this local resource may have been utilized in the past. A simple search in Lil'Sorrel for "diabase" materials yielded 61 specimens recovered from 32 contexts ranging from surface finds to shovel test units (this number will grow, as the database migration is still in progress). These can be exported (as a Microsoft Office Excel table), converted to a comma separated values (CSV) format, and imported into a GIS (i.e., QGIS 2.0.1) to allow for low-usage-barrier geospatial analysis by either the Collections Manager or another subject matter expert. The search-export feature, combined with FOSS GIS, permits more efficient data sharing between the CRM Program and the scientific community.

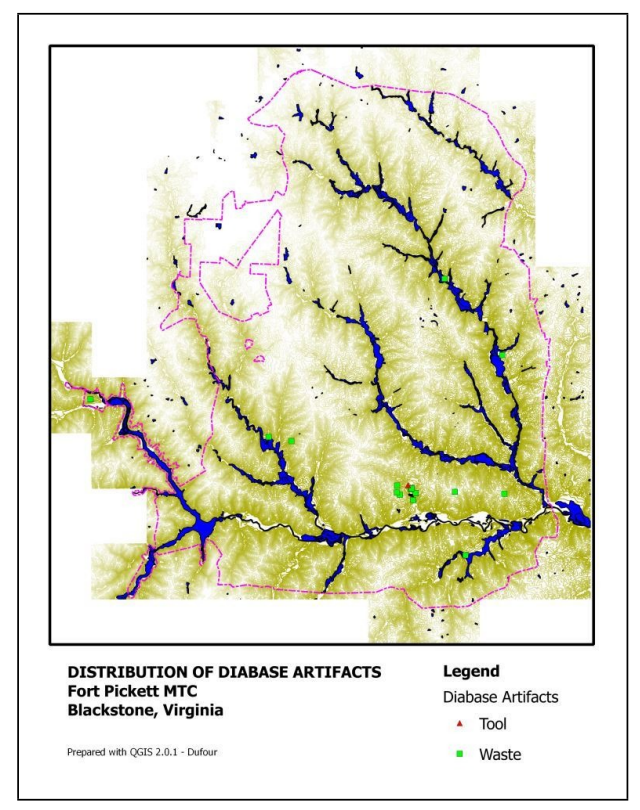

Figure 9.3: Example QGIS mapping output from Lil'Sorrel queries of diabase artifacts at VAARNG

An MS Access-based system has allowed the CRM Program to rapidly develop and deploy Lil'Sorrel, and thereby demonstrate its potential and encourage support from both inside and outside the CRM Program. It has also afforded an opportunity to integrate data from the curation program with other databases that have been developed to manage the CRM Program's projects and geospatial information. Unfortunately, Lil'Sorrel faces serious challenges with MS Access: it limits its size to 100,000 entries and 2.0 GB; the backend database resides on the VAARNG's network and can only be accessed internally by CRM Program personnel; and there is no guaranteed funding source available to research, develop, or deploy a replacement. 
There are numerous opportunities to overcome these challenges with FOSS. While it is a common misconception that the Department of Defense forbids Open Source Software (OSS, as FOSS is termed by the DoD), its departments have made widespread use of such applications including web browsers (e.g., Mozilla Firefox), scripting languages (e.g., Python, PHP) and relational database systems (e.g., MySQL, PostgreSQL). According to a recent white paper sponsored by the Office of the Secretary of Defense, OSS provides the military with increased flexibility, faster delivery, more innovation, and information assurance at lower costs than proprietary "off the shelf" resources (Scott et al. 2011). The DoD has issued guidance through its Chief Information Officer to encourage the adoption and use of OSS throughout the Department and its affiliates (Wennergren, 2009).

This presents Lil'Sorrel with two available paths. The first is to replace Lil'Sorrel outright with an actual museum management program such as CollectiveAccess or CollectionSpace, two freely distributed open source systems developed specifically for managing collections held by museums, archives, and historical societies of all sizes worldwide. The other alternative is to adapt Lil'Sorrel to an FOSS equivalent of MS Access such as Glom, Kexi, or Wavemaker (in conjunction with either MySQL or PostgreSQL for the backend database). Although these will not deploy as rapidly as the "ready out-of-the-box" options mentioned above, FOSS applications will afford the CRM Program the ability more readily retain its ability to integrate the various databases that govern its operations. All of these are web-based applications, which hold the possibility for increased access to the VAARNG Archaeology Collection through a secure server. As the mission of the Department of Military Affairs is to administer the National Guard and its facilities in Virginia, it is not a research institution and therefore cannot function as such. Still, the CRM Program will continue to evaluate these and similar options in the hope of extending access of its archaeological resources to those institutions that would best benefit.

\subsection{Use Case Three: FOSS GIS in the University}

FOSS GIS is a boon to educator-researchers in a university system, in that it provides an exceedingly useful and accessible toolkit with which students at all levels can develop geospatial competencies and utilize geospatial data for a number of course-related projects. Furthermore, the accessibility of these geospatial tools lowers a number of barriers and creates a very open and fluid dynamic for entry of student research assistants into the productive process for creation and analysis of geospatial data. The examples in this section are from coursework, and research activities with student involvement, at Indiana University South Bend. These activities were part of the undergraduate curriculum in anthropological archaeology that includes courses developed on the Massachusetts Institute of Technology's model of "technology-enabled active learning” (TEAL) that includes training in software applications to help facili- 
tate deeper and more functional comprehension of scientific concepts in a university setting (e.g. Barak and Dori 2005; Dori and Belcher 2005). The examples to be discussed in this section include: (1) dedicated courses in GIS methods, based completely or partially in Quantum GIS; (2) the uses of Google Earth to support geospatial comprehension in introductory and advanced courses in archaeological science; and (3) the uses of QGIS to facilitate student participation in geospatial data collection, analysis, and presentation related to archaeological field schools and other research projects in support of and collaboration with faculty.

\subsubsection{GIS Classes}

A first question to be answered of FOSS GIS is simply, "Can you actually teach a meaningful GIS class with it?” The answer is, “Yes!” A dedicated course in GIS using FOSS applications can be a rewarding experience for the instructor as well as the students since all involved can utilize the software on any available computer, not just simply from a dedicated lab or other locations where proprietary licenses are installed (or a limited number are swapped between available installations). The generally lower system requirements for FOSS GIS also makes student use of their personal computer for coursework an almost certain success.

The introductory course described here used Quantum GIS (v.1.6 CopiapÃş) as the primary software for instruction. The class was primarily about vector-based data collection, management, analyses, and map production. Training on raster data usage was limited to manipulations that added interpretive value to map production, such as clipping, and instructions that translated raster projections to correspond with vector projections (QGIS 1.6 only had on-the-fly projection for vector data, later versions have this feature for all data). University technology support staff were requested to install QGIS on all general campus computers (running Windows 7), and students were provided instructions, in-class examples, and online guidance to install QGIS through their personal Windows, Mac, and Linux operating system computers. The ease and elegance of multiple operating system installation created an immediate environment of competency, camaraderie, and ownership on the part of the students.

As a fairly standard introduction to mostly vector-based data analyses, the course progressed over the course of a semester through a series of lessons and exercises that explained data management mainly through the examples of shapefiles and KML. Cartographic, general GIS, and software specific references were required textbooks, including Making Maps: A Visual Guide to Map Design for GIS (Krygier and Wood 2005), How to Lie with Maps (Monmonier 1996), and the Quantum GIS User Guide (QGIS Development Team 2011 [2013]). The instructor provided students with useful example web resources for each lesson topic. Students were encouraged to explore user community forums on their own outside of class. Students also created collaborative "quick use guides" in class-shared Google Docs, based on their own trials and forum 
searches. In total, the collaborative-yet-self-reliant practices of digital literacy that are a part of good practice in the FOSS GIS community helped students to develop competencies and skills across a wide range of associated technologies which would serve them well in future GIS classes or in GIS workplaces.

\subsubsection{Introductory and Advanced Archaeology Classes}

Freely available mapping applications create many new affordances and opportunities for students to learn core course topics and geospatial concepts in tandem. For courses where there is neither available time nor prerequisite preparation for a fullfeatured GIS application, the free use of Google Earth is a pragmatic and effective choice. In a freshman-level class on human evolution and archaeology, Google Earth provides students with the capacity to create, share, combine, and review (as part of an overall TEAL process Wells and VanderVeen n.d.) point and polygon data sets such as modern and extinct primate distributions; geolocational data from the UNESCO World Heritage List database, and other heritage organizations can be downloaded and manipulated in order to learn about traits and distributions of international heritage properties. At more senior levels, Google Earth is suitable for mapping individual and group research on heritage sites at regional or global scales. Students can annotate their KML data with image links and hypertext descriptions that build a functional public outreach project from their original research that is easily published through Google Maps or any other KML viewer. An archaeological methods class can engage in a systematic surface survey based on a geolocated datum and visualize their data quickly and easily using either (1) algebraic coordinate calculation and plotting manually or through CSV to KML transformation using numerous third party FOSS applications or websites, or (2) radial point plotting using Google Earth's ruler tool.

\subsubsection{Archaeological Field Schools and Other Research}

A field school is an arena the demonstrates the immense pedagogical and research potential of FOSS GIS applications. Quantum GIS is the perfect application for geospatial data management and analysis during an ongoing field project, to integrate students into the process. The lightweight, multiple platform capability, and of course freely shareable installation of QGIS makes GIS work a possibility on every project computer, and on available student computers as well.

QGIS has fairly low and readily attainable system requirements, although these are not specifically defined by the developers due to the wide variety of operating systems they support. On recent archaeological field schools, QGIS 1.6, 1.7, and 1.8 all ran well on bargain-priced, ruggedized netbooks from $2 \mathrm{GoPC}$. These systems each had a 
1.6 GHz processor, 1GB of RAM, and a 1024 by 600 pixels (compare to ArcGIS minimum system requirements of a $2.2 \mathrm{GHz}$ processor and $2 \mathrm{~GB}$ of RAM).

The distribution of FOSS GIS-ready laptops throughout the project made on-site data entry a viable possibility that kept the notebook-to-digital stream flowing in near to real time. Through structured file sharing among project participants, remaining data entry and rudimentary analyses could be conducted during evenings by interested students on their personal computers. In sum, QGIS afforded the project the opportunity to develop a faster workflow, and students the opportunity to learn and actualize upon training with geospatial data concepts in a low-overhead and licensefree (no swapping, no dongles!) scenario. For some students this training was directly applicable to later projects in a related archaeological laboratory course.

\subsection{Conclusion}

This chapter has provided an introduction to ways in which free and open-source geographic information systems and other free geospatial software can be integrated into a professional workflow in several arenas of archaeological activity. Archaeologists are encouraged to begin accessing these resources and participating in user communities, beginning with the guideposts described here. The ability to use GIS and geospatial applications outside of specialized labs, now on any available and moderatelyaged computer, should help promote more rigorous training, project-level, and disciplinary activities in data sharing and reuse. The "open" concept is not just for software, but for archaeological data in general (cf. Kansa et al. 2011; Anderson et al. 2010)!

At the university, GIS and geospatial training and concepts, at every level in archaeology, should no longer be relegated to a select few who have obtained the necessary equipment and software, which have themselves often been expensive and with significant use limitations related to license restrictions. FOSS GIS and other free geospatial software applications should be a part of every archaeological degree program from the undergraduate through the doctoral, and given a priority equivalent to database management and statistics in curriculum design. Indeed, GIS and geospatial training need no longer be separate from the other data-driven portions of a curriculum; maps should be considered as another mode of freely accessible visualization ("carto graphs" should be taught alongside line graphs and bar graphs) that facilitates comprehension of a dataset for analytical and outreach purposes.

In the compliance and research workplaces, GIS and geospatial data production, visualisation, and dissemination, should no longer be constrained by limitations of cost and accessibility. Many smaller laboratories, public and private, run on a tight budget and proprietary GIS licensing costs and restrictions may literally price some professionals out of the marketplace. Within the professional archaeological community, the broader employment of FOSS GIS should promote conversations with heritage management agencies, funding agencies, and curatorial facilities to augment 
existing frameworks for best practices in data management and publication (e.g. Archaeology Data Service / Digital Antiquity 2011; Open Context 2012; SAA (Society for American Archaeology) 2013; WLP (Shelby White and Leon Levy Program for Archaeological Publications) 2013) for local needs in a way that maintains data interoperability and reuse for the long term. The availability of FOSS GIS and geospatial freeware should also promote greater technological emphases in public outreach with spatial information, allowing the stakeholding public to engage in a reciprocal cycle of data production and consumption with the archaeological community (e.g. Beale 2012; Harris 2012; Hochstetter et al. 2011; Wells and McCullough 2009).

\section{Bibliography}

Anderson, D. G., Miller, D. S., Yerka, S. J., Gillam, J. C., Johanson, E. N., Anderson, D. T., Goodyear, A. C. and Smallwood, A. M. (2010), 'PIDBA (Paleoindian Database of the Americas) 2010: Current Status and Findings', Archaeology of Eastern North America 38, 63-90.

Andersson, A., Hallberg, N. and Timpka, T. (2003), 'A model for interpreting work and information management in process-oriented healthcare organisations', International Journal of Medical Informatics 72(1), 47-56.

Archaeology Data Service / Digital Antiquity (2011), 'Guides to good practice'. URL: http://guides.archaeologydataservice.ac.uk/g2gp/Main

Beale, N. (2012), 'How community archaeology can make use of open data to achieve further its objectives', World Archaeology 44(4), 612-633.

Coleman, E. G. (2013), Coding freedom: The ethics and aesthetics of hacking, Princeton University Press.

Creative Commons (2009), 'Attribution-ShareAlike 3.0 Unported (CC BY-SA 3.0)'.

URL: http://creativecommons.org/licenses/by-sa/3.0/

Creative Commons (2013), 'History - creative commons'. URL: http://creativecommons.org/about/history

Dempsey, C. (2012), 'Open Source GIS and Freeware GIS Applications', GIS Lounge. URL: http://www.gislounge.com/open-source-gis-applications/

Eclipse Foundation (2007), 'Eclipse Distribution License - v1.0'. URL: http://www.eclipse.org/org/documents/edl-v10.php

ESRI (1998), 'ESRI Shapefile Technical Description'. URL: http://www.esri.com/library/whitepapers/pdfs/shapefile.pdf

ESRI (2013), 'Geodatabase Overview'. URL: http://www.esri.com/software/arcgis/geodatabase

Graser, A. (2013), Learning QGIS 2.0, Packt Publishing Ltd.

Harris, T. M. (2012), 'Interfacing archaeology and the world of citizen sensors: exploring the impact of neogeography and volunteered geographic information on an authenticated archaeology', World Archaeology 44(4), 580-591.

Hochstetter, F. T., Haoa, S. R., Lipo, C. P. and Hunt, T. L. (2011), 'A public database of archaeological resources on easter island (rapa nui) using google earth', Latin American Antiquity 22(3), 385397.

Kansa, E. C., Kansa, S. W. and Watrall, E. (2011), 'Archaeology 2.0: new approaches to communication and collaboration', Cotsen Digital Archaeology series .

Kaplan, B., Schold, J. and Meier-Kriesche, H.-U. (2003), 'Overview of large database analysis in renal 
transplantation', American Journal of Transplantation 3(9), 1052-1056.

Kintigh, K. (2006), 'The promise and challenge of archaeological data integration', American Antiquity pp. 567-578.

Kling, R., Rosenbaum, H. and Sawyer, S. (2005), Understanding and communicating social informatics: A framework for studying and teaching the human contexts of information and communication technologies, Information Today, Inc.

Neumann, T. W. and Sanford, R. M. (2001), 'Cultural resources archaeology: an introduction'.

Open Context (2012), 'Open Context Data Publishing: Editorial Policies and Author Guidelines'. URL: http://alexandriaarchive.org/wp-content/uploads/2012/04/OpenContext_DataPublishing_ Policies\&Guidelines.pdf

Open Source Initiative (2013), 'The open source definition'. URL: http://opensource.org/osd

OSGeo (Open Source Geospatial Foundation) (2013a), 'Open Source GIS History - OSGeo Wiki'. URL: http://wiki.osgeo.org/wiki/Open_Source_GIS_History

OSGeo (Open Source Geospatial Foundation) (2013b), 'Welcome to OSGeo-Live 7.0-OSGeo-Live 7.0 Documentation'.

URL: http://live.osgeo.org/en/index.html

Parr, C. (2011), 'From the ground up: Best practices for balancing usability with theoretical utility in archaeological databases', Society for American Archaeology Annual Meeting .

Raymond, E. (2000), 'The cathedral and the bazaar'. URL: http://www.catb.org/esr/writings/cathedral-bazaar/

Ross, S., Sobotkova, A., Ballsun-Stanton, B. and Crook, P. (2013), 'Creating eresearch tools for archaeologists: The federated archaeological information management systems project', Australian Archaeology (77), 107.

SAA (Society for American Archaeology) (2013), 'Society for american archaeology guidance regarding national science foundation archaeological data management plans'. URL: http://www.nsf.gov/sbe/bcs/arch/SAA_Data_Management_Plan_Guidance.pdf

SHA (Society for Historical Archaeology) (2011), 'Sha artifact cataloging system'. URL: http://www.sha.org/research/artifact_cataloging_system.cfm

Sherman, G. (2012), The Geospatial Desktop: Open Source GIS \& Mapping, Locate Press; 2nd edition.

Snow, D. R., Gahegan, M., Giles, C. L., Hirth, K. G., Milner, G. R., Mitra, P. and Wang, J. Z. (2006), 'Cybertools and archaeology', Science 311(5763), 958-959.

Steiniger, S. (2013), 'SourceForge.net: Open Source GIS Software'. URL: http://sourceforge.net/userapps/mediawiki/mentaer/index.php?title=0pen_Source_GIS_ Software

Steiniger, S. and Bocher, E. (2009), 'An overview on current free and open source desktop GIS developments', International Journal of Geographical Information Science 23(10), 1345-1370.

Steiniger, S. and Hay, G. J. (2009), 'Free and open source geographic information tools for landscape ecology', Ecological Informatics 4(4), 183-195.

Steiniger, S. and Hunter, A. J. (2013), 'The 2012 free and open source GIS software map-a guide to facilitate research, development, and adoption', Computers, Environment and Urban Systems 39, 136-150.

Thiede, R., Sutton, T., Düster, H. and Sutton, M. (2013), The Quantum GIS Training Manual: A Comprehensive Introduction to Quantum GIS, Locate Press.

Thiru, K., Hassey, A. and Sullivan, F. (2003), 'Systematic review of scope and quality of electronic patient record data in primary care', BMJ 326(7398), 1070.

Wells, J. (2011), 'Four States of Mississippian Data: Best Practices at Work Integrating Information from Four SHPO Databases in a GIS-Structured Archaeological Atlas'. 
URL: http://visiblepast.net/see/americas/four-states-of-mississippian-data-best-practices-atwork-integrating-information-from-four-shpo-databases-in-a-gis-structured-archaeologicalatlas/

Wells, J. and McCullough, R. (2009), 'Multiple scales of data on falls mississippian settlement practices', Indiana Archaeology p. 56.

Wells, J. and VanderVeen, J. (n.d.), 'Anthropological pedagogy through technology enabled active learning in undergraduate education'.

Wennergren, D. (2009), 'Clarifying guidance regarding open source software (OSS)'.

URL: http://dodcio.defense.gov/Portals/0/Documents/FOSS/20090SS.pdf

Wikipedia (2013), 'List of geographic information systems software'.

URL: http://en.wikipedia.org/w/index.php?title=List_of_geographic_information_systems_ software\&oldid $=569623888$

Williams, S. (2002), 'Free as in freedom: Richard Stallman's crusade for free software'.

URL: http://oreilly.com/openbook/freedom/index.html

WLP (Shelby White and Leon Levy Program for Archaeological Publications) (2013), 'The Shelby White-Leon Levy Program: Data Management Plan'.

URL: http://www.fas.harvard.edu/ semitic/wl/dataplan.html 